
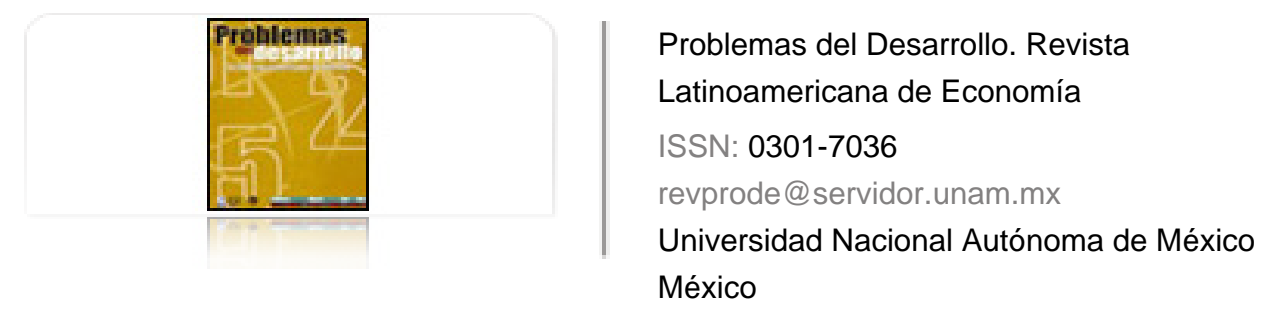

Ocegueda Hernández, Juan Manuel; Castillo Ponce, Ramón Amadeo; Varela Llamas, Rogelio CRECIMIENTO REGIONAL EN MÉXICO: ESPECIALIZACIÓN Y SECTORES CLAVE Problemas del Desarrollo. Revista Latinoamericana de Economía, vol. 40, núm. 159, octubrediciembre, 2009, pp. 61-84

Universidad Nacional Autónoma de México

Distrito Federal, México

Disponible en: http://www.redalyc.org/articulo.oa?id=11820103004

Cómo citar el artículo

- Número completo

- Más información del artículo

Página de la revista en redalyc.org

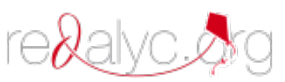

Sistema de Información Científica

Red de Revistas Científicas de América Latina, el Caribe, España y Portugal Proyecto académico sin fines de lucro, desarrollado bajo la iniciativa de acceso abierto 


\title{
CRECIMIENTO REGIONAL EN MÉXICO: ESPECIALIZACIÓN Y SECTORES CLAVE
}

\author{
Juan Manuel Ocegueda Hernández* \\ Ramón Amadeo Castillo Ponce** \\ Rogelio Varela Llamas***
}

Fecha de recepción: 18 de mayo de 2009. Fecha de aceptación: 13 de octubre de 2009.

\section{Resumen}

En este trabajo se estudia la función de la especialización en el desempeño económico de los estados de México, estimándose una ecuación de crecimiento aumentada con un índice de especialización que captura las ganancias de productividad por la reasignación de recursos hacia sectores con rendimientos crecientes a escala y una variable que mide el efecto emparejamiento tecnológico (catch up). Este ejercicio se distingue de otros similares en que se utilizan índices de especialización desagregados a nivel de ramas y subramas de actividad económica y en que el análisis se centra en el impacto de sectores clave, los cuales se identifican siguiendo los criterios establecidos por la nueva teoría del crecimiento (NTC) y la teoría poskeynesiana (TPK). Lo anterior permite ubicar las actividades económicas que contribuyen de manera especial al crecimiento económico de los estados y contrastar la validez de algunos argumentos presentes en la discusión teórica actual.

Palabras clave: especialización, crecimiento económico, sectores clave, desarrollo regional.

Clasificación JEL: R11

* Profesor de la Facultad de Economía y Relaciones Internacionales de la Universidad Autónoma de Baja California. Correo electrónico: jmocegueda@uabc.mx

** Profesor de la Facultad de Economía y Relaciones Internacionales de la Universidad Autónoma de Baja California. Correo electrónico: racastillo2000@yahoo.com

**** Profesor de la Facultad de Economía y Relaciones Internacionales de la Universidad Autónoma de Baja California. Correo electrónico: varelall@uabc.mx

Los autores agradecen las recomendaciones de dos dictaminadores anónimos que contribuyeron a enriquecer este trabajo. 
Abstract

This article studies the role of specialization in the economic performance of Mexico's states, estimating an equation for growth augmented by a specialization index that captures gains in productivity by reallocating resources towards sectors with growing returns to scale and a variable that measures the catch-up effect. This exercise is distinguished from other similar ones by its utilization of specialization indices broken down at the branch and economic activity levels where the analysis focuses on the impact of the key sectors, which are identified by following the criteria established by the new theory of growth (NTG) and Post-Keynesian theory (PKT). This makes it possible to place the economic activities that contribute in a special way to economic growth in the states and to contrast the validity of some arguments present in the present theoretical debate. Key words: specialization, economic growth, key sectors, regional development.

\section{Résumé}

Dans ce travail il est mené une étude de la fonction de la spécialisation dans la performance économique des états du Mexique, considérant une équation de croissance accrue avec un indice de spécialisation qui capture les gains de productivité par réassignation de revenus dans des secteurs ayant des rendements croissants à échelle et une variable qui mesure l'effet d'égalisation technologique (catch up). Cet exercice se distingue d'autres similaires en cela que les indices de spécialisation utilisés sont décomposés au niveau des branches et sous-branches d'activité économique et que l'analyse est centrée sur l'impact des secteurs clés, lesquels sont identifiés selon les critères établis par la théorie de croissance (NTC) et la théorie post-keynesienne (TPK). Ceci permet de situer les activités économiques qui contribuent de façon particulière à la croissance économique des états et contrôler la validité de certains arguments présents dans le débat théorique actuel.

Mots clés: spécialisation, croissance économique, secteurs clés, développement régional.

\section{Resumo}

Neste trabalho estuda-se a função da especialização no desempenho econômico dos estados do México, estimando-se uma equação de crescimento aumentada com um índice de especialização que captura os ganhos de produtividade pela redistribuição de recursos para setores com rendimentos crescentes a escala e uma variável que mede o efeito emparelhamento tecnológico (catch up). Este exercício se distingue de outros similares em que se utilizam índices de especialização desagregados a nível de ramos y sub-ramos de atividade econômica e em que a análise se centra no impacto de setores chave, os quais se identificam seguindo os critérios estabelecidos pela nova teoria do crescimento (NTC) e a teoria pos-keynesiana (TPK). Isto permite localizar as atividades econômicas que contribuem de maneira especial para o crescimento econômico dos estados e contrastar a validez de alguns argumentos presentes na discussão teórica atual.

Palavras-chave: especialização, crescimento econômico, setores-chave, desenvolvimento regional.

\section{Desarrollo}




\section{Introducción}

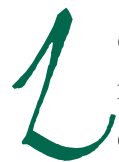

os datos disponibles muestran a México como un país de grandes contrastes regionales que se manifiestan a través de disparidades en los ingresos per

cápita, en la dotación de infraestructura y en los indicadores educativos y de bienestar social. De igual manera, se observan diferencias importantes entre las tasas de crecimiento de los estados, que contribuyen a que persista dicha situación, lo que es tanto causa como consecuencia de las enormes desigualdades geográficas. Esta afirmación supone la existencia de dinámicas acumulativas circulares, que en las entidades federativas más pobres operan como un freno al desarrollo, mientras que en las más ricas implican círculos virtuosos que promueven y retroalimentan el proceso de crecimiento económico.

Muchos trabajos han intentado explicar las desigualdades regionales en México recurriendo a diferentes enfoques teóricos y a metodologías alternativas, que van desde los tradicionales ejercicios de convergencia sigma y beta (absoluta y condicional), hasta la verificación empírica de la leyes de Kaldor o la ley de Verdoom, por citar sólo algunos ejemplos ${ }^{1}$. En estos ejercicios se ha medido el impacto de variables como educación, infraestructura pública, gasto público, migración y tipo de especialización productiva sobre las trayectorias de crecimiento y los niveles de ingreso per cápita de los estados. Aunque la mayoría concluyen que las variables analizadas impactan el desempeño económico, las explicaciones que derivan de los resultados y, por ende, las recomendaciones políticas, dependen del enfoque teórico adoptado por cada autor.

Los estudios que introducen las dinámicas acumulativas circulares para explicar la divergencia económica internacional no son homogéneos, se distinguen por lo menos dos grandes escuelas: la nueva teoría del crecimiento (NTC) y la teoría poskeynesiana (TPK). Si bien los argumentos en torno a las fuerzas que se ponen en movimiento para generar dichos procesos acumulativos difieren, ambas corrientes ponen el énfasis en la importancia de la especialización que incrementa la productividad a través del aprendizaje, independientemente del tipo de bienes que se produzcan, o mediante la creación de ventajas asociadas a la producción de ciertos bienes que presenten mayores oportunidades tecnológicas o enfrenten demandas más dinámicas (Dalum, Laursen y Verspagen, 1999).

Véanse entre otros Esquivel, 1999; Messmacher, 2000; Arroyo, 2001; Gamboa y Messmacher, 2003; Fuentes y Mendoza, 2003; Ocegueda, 2003; Calderón y Martínez, 2005; Calderón y Tykhonenko, 2007.

Vol. 40, núm. 159, octubre-diciembre / 2009 
La NTC destaca la importancia de la especialización en actividades con altas tasas de progreso técnico endógeno y externalidades tecnológicas, sosteniendo que los países cuya orientación productiva es hacia los bienes de alto contenido tecnológico pueden crecer más rápido que aquellos que producen bienes de tipo tradicional, debido a que son mayores sus oportunidades de innovación (Romer, 1990; Grossman y Helpman, 1991). Sin embargo, otra vertiente de esta escuela centra su análisis en los efectos favorables del aprendizaje por experiencia y los rendimientos a escala sobre el desempeño económico, independientemente de las áreas productivas en las que cada país se especialice (Romer, 1986; Lucas, 1988). La TPK, con un soporte teórico distinto, sostiene que la especialización en actividades con rendimientos crecientes a escala acelera el incremento de la productividad en el conjunto de la economía, ya sea como resultado del progreso técnico inducido o por la absorción de recursos provenientes de actividades menos productivas (Kaldor, 1970). Asimismo, la especialización puede tener efectos favorables sobre el crecimiento económico cuando se orienta a la producción de bienes con altas elasticidades ingreso $(\varepsilon)$, debido a que eleva la competitividad en el comercio internacional y permite la apropiación de una fracción creciente de la demanda externa a medida que ésta se expande (Thirlwall, 1979; Thirlwall y Dixon, 1979).

El presente documento tiene como objetivo central estudiar el impacto de la especialización en la configuración de las desigualdades regionales actuales, si bien por las restricciones de la información disponible el estudio se circunscribe al periodo 1988-2003. Esta periodización tiene la desventaja de excluir las décadas previas, sobre todo la de 1980, en la que algunos autores identifican un punto de inflexión en el desarrollo regional del país, al pasarse de un crecimiento convergente a otro de carácter divergente (Arroyo, 2001; Fuentes, 2003). Aunque con ello se omite información valiosa de esta etapa de la historia económica de México, también se tiene la ventaja de analizar la era postapertura sin los sesgos que introducen los años de crisis y ajuste (1982-1987), y sin los problemas de cambio estructural que implica mezclar años en que prevalecieron modelos de desarrollo sustancialmente diferentes. La hipótesis que guía esta investigación es que los patrones de especialización seguidos en las entidades federativas, al definir condiciones estructuralmente distintas para el desarrollo económico, han determinado diferencias regionales de ingresos y tasas de crecimiento.

Se formulan dos ejercicios: en el primero se analizan y correlacionan distintos índices de especialización (IE) con indicadores de desempeño; en el segundo se estima una ecuación de crecimiento introduciendo $\mathrm{IE}_{\mathrm{i}}$ por actividades económicas 
seleccionadas, considerando tres y cuatro dígitos de la Clasificación Mexicana de Actividades y Productos (CMAP), así como una variable que captura el efecto emparejamiento tecnológico. Este ejercicio se distingue de otros similares realizados para México en que se utilizan IE con un mayor nivel de desagregación y en que el análisis se centra en el impacto de los sectores clave, los cuales se identifican siguiendo los criterios establecidos por la NTC y la TPK. Esto permite identificar simultáneamente las actividades económicas con una contribución especial al crecimiento y contrastar la validez de algunos argumentos presentes en la discusión teórica actual.

El documento se divide en cuatro partes: en la primera se presenta una breve revisión de la teoría; en la segunda se realiza una clasificación de actividades económicas siguiendo los criterios que proponen la NTC y la TPK; en la tercera se analiza la relación entre especialización y crecimiento a través de herramientas estadísticas y econométricas. Finalmente, se desarrollan algunas reflexiones sobre los principales resultados del trabajo.

\section{La función de la especialización}

La idea de que la especialización en la producción influye en el crecimiento económico no es nueva, se remonta por lo menos a los trabajos de Adam Smith y David Ricardo, quienes identificaron dos canales a través de los que la especialización induce un mejor desempeño económico: a) como resultado del aprendizaje asociado a la experiencia que permite aumentar la productividad del trabajo y la obtención de rendimientos crecientes, independientemente del tipo de bienes que se produzcan (enfoque smithiano), y $b$ ) como resultado de las ventajas que se obtienen cuando la producción se orienta hacia las áreas y bienes que ofrecen las mejores oportunidades tecnológicas o de ventas en los mercados internacionales (enfoque ricardiano).

Los enfoques smithiano y ricardiano pueden encontrarse en diversas teorías sustentados con distintos argumentos. La NTC formula modelos en ambas direcciones. Para Lucas (1988), quien asume que la formación de capital humano depende del aprendizaje por experiencia, el libre comercio conduce a que los países se especialicen en la producción de aquel bien en el que poseen ventajas comparativas. A través del proceso de aprender haciendo, la productividad se eleva, la ventaja comparativa aumenta y el desempeño económico mejora, independientemente del tipo de bien que se produzca (Meliciani, 2001). La especialización en un rango reducido de productos permite aprovechar los rendimientos crecientes resultantes de las

Vol. 40, núm. 159, octubre-diciembre / 2009 
economías de escala y de la reasignación de recursos (Rivera Bátiz y Romer, 1991; Rivera Bátiz y Xie, 1993). En Grossman y Helpman (1991), cada actividad tiene su propia tasa de crecimiento de la productividad debido a que las oportunidades tecnológicas difieren, por tanto, la especialización en sectores de alta tecnología con elevadas tasas de innovación acelera el crecimiento económico. En este caso, el libre comercio permite aprovechar y retroalimentar las ventajas del patrón de producción adoptado, impulsando el progreso técnico, ya sea porque el intercambio de ideas aumenta el stock de conocimientos, porque se evita la duplicación de esfuerzos en la investigación científica y tecnológica, o porque la ampliación de la escala de producción incentiva la innovación.

Al margen de la corriente principal se han desarrollado otras perspectivas analíticas que establecen una relación estrecha entre comercio, especialización y crecimiento, pero en donde, a diferencia de las teorías anteriores, las fuerzas de la demanda gobiernan la economía en el largo plazo. Entre éstas puede identificarse a la TPK que, siguiendo un enfoque ricardiano, destaca la importancia de ocuparse en actividades con rendimientos crecientes a escala o de producir bienes con altas elasticidades ingreso (Jungmittag, 2004). Si los mercados se expanden más rápidamente para algunos bienes que para otros y además la expansión del producto afecta positivamente la productividad de los factores, el tipo de bienes que se produzcan puede determinar la diferencia entre un crecimiento más rápido o más lento. En tal caso, producir bienes con altas elasticidades ingreso o en actividades con rendimientos crecientes a escala que promueven el progreso técnico, son las mejores opciones para alcanzar una tasa de crecimiento alta. Ésta es la perspectiva que adopta la TPK, particularmente en los trabajos de Kaldor (1966, 1970) y Thirlwall (1980, 2002).

Ambas visiones, la smithiana y la ricardiana, implican políticas estatales diferenciadas para fortalecer la especialización. El argumento smithiano asume que las dotaciones relativas de factores son las que deben guiar dicho proceso, independientemente del tipo de bienes y sectores favorecidos, por lo que la acción estatal, más que a promover el desarrollo de ciertos sectores, debe concentrarse en fortalecer las ventajas comparativas de la economía aumentando los stocks de capital humano y conocimientos. Por su parte, el argumento ricardiano implica que la producción de bienes industriales con altas tasas de aprendizaje, rendimientos crecientes a escala o elevadas elasticidades ingreso, conduce a que algunas economías tomen ventaja sobre otras, particularmente sobre aquellas que se especializan en la producción de bienes primarios o bienes industriales tradicionales de bajo contenido tecnológico. Por tanto, se justifican acciones de política económica para favorecer el desarrollo de sectores productivos estratégicos. 
La NTC sostiene que la acumulación de conocimientos y capital humano son las principales fuerzas que determinan la tasa de crecimiento económico, y sus ritmos de acumulación son directamente proporcionales a la fracción de recursos humanos y financieros que la sociedad y las empresas destinan a estos sectores. Así, los desempeños diferenciados entre economías se asocian al acceso limitado o desigual a cualquiera de estos recursos, lo cual es independiente de las fuerzas de la demanda.

La TPK identifica a la demanda externa como la principal fuerza expansiva a través de su efecto sobre las exportaciones, cuyo dinamismo permite que la economía ingrese en una dinámica acumulativa circular sin restricciones, como en Kaldor $(1966,1970)$ y Dixon y Thirlwall (1975), o en una trayectoria de crecimiento equilibrado pero restringida por la balanza de pagos, como en Thirlwall (1979), Thirlwall y Dixon (1979) y Thirlwall (1980). Una limitación del primer tipo de modelos es que generan una dinámica explosiva que se traduce en la sobreestimación empírica de la tasa de crecimiento, lo cual puede acotarse con la introducción de una condición de equilibrio, como se hace en el segundo tipo de modelos. En ambos se puede inferir, aunque en el primer tipo es menos evidente, que dada la demanda externa, el tipo de especialización determina la capacidad exportadora y el ritmo al que crece la productividad.

En los siguientes apartados se desarrolla un análisis empírico sobre la relación entre especialización y desempeño económico siguiendo el enfoque ricardiano pero sin distinguir entre los argumentos de la NTC y los de la TPK, lo cual supone que cualquier evidencia favorable sobre la existencia y solidez de dicha relación debería ser consistente con cualquiera de ellas. A continuación se procede a identificar los sectores con atributos especiales, a los que se les denomina sectores clave.

\section{Los sectores clave}

Una vez que se acepta la importancia de la especialización para determinar el comportamiento de la productividad y el progreso técnico, el siguiente paso es identificar los sectores clave. Las actividades económicas se pueden clasificar de acuerdo con tres criterios: 1) por el tipo de factores que usan intensivamente; 2) por el nivel de la tecnología empleada, y 3 ) por el valor de las elasticidades ingreso ( $\varepsilon$ ) en el comercio internacional. Ello tiene la ventaja de que permite aproximar la evidencia empírica a la teoría, pues se llega a agrupaciones de actividades económicas o de productos que se asemejan a las que refieren los cuerpos teóricos analizados.

Vol. 40, núm. 159, octubre-diciembre / 2009 
En el cuadro 1 se presenta una tipología de sectores siguiendo los criterios 1 y 2 , así como la Clasificación Internacional Industrial Uniforme, revisión 2 (CIIU rev. 2), la cual es consistente con la CMAP. Se utilizan tres y cuatro dígitos dependiendo del nivel de desagregación necesario en cada caso particular, lo cual se determina en función del nivel de homogeneidad sectorial. Cuando un grupo de actividades es homogéneo, en el sentido de que se ajusta a un criterio particular, se identifica con tres dígitos; cuando al interior de éste algunas actividades no se ajustan al criterio utilizado para la mayoría, el análisis se lleva a cuatro dígitos. Ambos criterios ( 1 y 2) se cumplen en las actividades manufactureras, no así en las agropecuarias, mineras y de servicios, para las que no fue posible conseguir información suficiente. La penúltima columna (mediana tecnología) se integra por dos subgrupos: el de tecnología mediaalta (A) y el de tecnología media-baja (B).

De acuerdo con esta clasificación, los sectores clave por su dinamismo y por su impacto en la productividad y el crecimiento económico son los denominados difusores de conocimiento y de alta tecnología. Sólo tres sectores cubren ambos requisitos: la industria farmacéutica (3521), máquinas de oficina, cálculo y procesamiento informático (3823) y equipo electrónico y de comunicaciones (3832). Una selección de sectores clave menos ambiciosa y quizá con mayor factibilidad para un país como México podría incluir a los de tecnología media alta, en donde se identifican siete: química industrial (351), otros productos químicos (3522), maquinaria no eléctrica (3821 y 3822), maquinaria y equipo eléctrico (3831 y 3833), industria automotriz (3841), equipo de transporte y sus partes (3842) e instrumental científico y equipo de precisión (385). Los últimos cinco cumplen también con el criterio de ser difusores de conocimiento. Los sectores tradicionales, a los que comúnmente se les atribuye poca capacidad para dirigir el proceso de crecimiento económico, se concentran entre los de baja tecnología, intensivos en recursos naturales e intensivos en mano de obra. Aquí se ubican principalmente las actividades agropecuario-forestales, la minería y las industrias alimentaria, textil, maderera y del papel.

El cuadro 2 relaciona los grupos de productos con mayor participación en el comercio internacional, calculándose sus respectivas elasticidades ingreso (criterio 3 ). Ésta se aproxima dividiendo la tasa de crecimiento de las exportaciones mundiales de cada grupo de bienes entre la tasa de crecimiento del ingreso mundial, bajo el supuesto de que los cambios en la demanda son independientes de las fluctuaciones de precios y que los gustos y preferencias son capturados por dicho parámetro. Aun cuando pueda resultar polémico este método de cálculo, es una opción atractiva debido a su sencillez, a la accesibilidad de la información necesaria y a que es posible justificar 
Cuadro 1

Clasificación de actividades económicas por la intensidad con que usan los factores productivos y por el nivel de tecnología

\begin{tabular}{|c|c|c|c|c|c|c|c|}
\hline SUBSECTORES & códiGO & $\begin{array}{c}\text { INTENSIVOS } \\
\text { EN RECURSOS } \\
\text { NATURALES }\end{array}$ & $\begin{array}{c}\text { INTENSIVOS } \\
\text { EN MANO } \\
\text { DE OBRA }\end{array}$ & $\begin{array}{c}\text { DIFUSORES } \\
\text { DE } \\
\text { CONOCIMIENTO }\end{array}$ & $\begin{array}{c}\text { BAJA } \\
\text { TECNOLOGÍA }\end{array}$ & \begin{tabular}{|c|} 
MEDIANA \\
TECNOLOGÍA
\end{tabular} & $\begin{array}{c}\text { ALTA } \\
\text { TECNOLOGÍA }\end{array}$ \\
\hline Agricultura y ganadería & 111 & $x$ & & & & & \\
\hline Madera y aserraderos & 121,122 & $x$ & & & & & \\
\hline Minería del carbón & 210 & $x$ & & & & & \\
\hline Extracción de petróleo y gas natural & 220 & $x$ & & & & & \\
\hline Minería metálica & 231,232 & $x$ & & & & & \\
\hline Minería no metálica & 291,292 & $x$ & & & & & \\
\hline Alimentos & 311,312 & $x$ & & & $x$ & & \\
\hline Bebidas & 373 & $x$ & & & $x$ & & \\
\hline Tabaco & 374 & $x$ & & & $x$ & & \\
\hline Manufacturas de textiles & 321 & & $x$ & & $x$ & & \\
\hline Confección de prendas de vestir & 322 & - & $x$ & & $x$ & & \\
\hline $\begin{array}{l}\text { Industria del cuero, pieles y sus productos, } \\
\text { excepto calzado }\end{array}$ & 323 & & $x$ & & $x$ & & \\
\hline Industria del calzado, excepto de hule y plástico & 324 & & $x$ & & $x$ & & \\
\hline Manufacturas de madera y corcho, excepto muebles & 331 & $x$ & & & $x$ & & \\
\hline $\begin{array}{l}\text { Fabricación y reparación de muebles de madera, } \\
\text { incluye colchones }\end{array}$ & 332 & & $x$ & & $x$ & & \\
\hline Manufacturas de papel y productos de papel & 341 & $x$ & $x$ & & $x$ & & \\
\hline Imprentas, editoriales e industrias conexas & 342 & & $x$ & & $x$ & & \\
\hline Manufacturas de químicos industriales & 351 & $x$ & & & & $A$ & \\
\hline $\begin{array}{l}\text { Manufacturas de otros productos químicos, } \\
\text { excepto industria farmacéutica }\end{array}$ & 3522 & $x$ & $x$ & & & $A$ & \\
\hline Industria farmacéutica & 3521 & & & $x$ & & & $x$ \\
\hline Refinación de petróleo & 353 & $x$ & & & & $B$ & \\
\hline $\begin{array}{l}\text { Industria del coque, incluye derivados } \\
\text { del carbón mineral y del petróleo }\end{array}$ & 354 & $x$ & & & & $B$ & \\
\hline Industria del hule & 355 & $x$ & & & & B & \\
\hline Elaboración de productos de plástico & 356 & & $x$ & & & $B$ & \\
\hline Alfarería, cerámica y materiales de arcilla & 367 & & $x$ & & & $B$ & \\
\hline Fabricación de vidrio y productos de vidrio & 362 & $x$ & & & & B & \\
\hline Manufacturas de otros minerales no metálicos & 369 & $x$ & & & & B & \\
\hline Industrias básicas del hierro y el acero & 371 & $x$ & & & & $B$ & \\
\hline Industrias básicas de metales no ferrosos & 372 & $x$ & & & & $B$ & \\
\hline $\begin{array}{l}\text { Fabricación de productos metálicos, } \\
\text { excepto maquinaria y equipo }\end{array}$ & 381 & & & $x$ & & $B$ & \\
\hline $\begin{array}{c}\text { Fabricación, reparación y/o ensamble de } \\
\text { maquinaria diversa, excepto eléctrica }\end{array}$ & 3821,3822 & & & $x$ & & $A$ & \\
\hline $\begin{array}{l}\text { Fabricación, reparación y/o ensamble de máquinas } \\
\text { de oficina, cálculo y procesamiento informático }\end{array}$ & 3823 & & & $x$ & & & $x$ \\
\hline Fabricación y/o ensamble de maquinaria y equipo eléctrico & 3831,3833 & & & $x$ & & A & \\
\hline $\begin{array}{l}\text { Fabricación y/o reparación de equipo electrónico y } \\
\text { de comunicaciones }\end{array}$ & 3832 & & & $x$ & & & $x$ \\
\hline Industria automotriz & 3841 & & & $x$ & & $A$ & \\
\hline $\begin{array}{l}\text { Fabricación, reparación y/o ensamble de equipo de transporte } \\
\text { y sus partes, excepto automóviles y camiones }\end{array}$ & 3842 & & & $x$ & & $A$ & \\
\hline $\begin{array}{l}\text { Fabricación, reparación y/o ensamble de instrumentos } \\
\text { y equipo de precisión }\end{array}$ & 385 & & & $x$ & & $A$ & \\
\hline Otras industrias manufactureras & 390 & & $x$ & & & $B$ & \\
\hline
\end{tabular}

Nota: La clasificación corresponde a la OCDE. En la columna mediana tecnología, A corresponde a un sector de tecnología media-alta; B, a tecnología media-baja.

Fuente: Se elaboró con datos tomados de Cimoli et al., 2005 y Hatzichronoglou, 1997. 
dichos supuestos tanto teórica como empíricamente ${ }^{2}$. No obstante, si el método causa dudas, el criterio de selección se puede ajustar y referirse a aquellos sectores en donde la demanda mundial crece más rápido, obteniéndose los mismos resultados.

La información se presenta para los periodos 1990-2006 y 2000-2006, lo que permite contar con un indicador de largo plazo y otro que muestre la tendencia reciente. Como es de esperarse, las manufacturas tienen $\varepsilon$ más altas que la minería y las actividades agropecuarias. A largo plazo, considerando la clasificación a tres dígitos, las mayores $\varepsilon$ corresponden a maquinaria y equipo de transporte $(382,383,384$ y 385$)$ y productos químicos (351 y 352 ), mientras que a cuatro dígitos sobresalen equipo de oficina y telecomunicaciones (3823 y 3832), productos automotrices (3841) y prendas de vestir (322). El análisis para este periodo está limitado porque no existen suficientes datos con una desagregación de cuatro dígitos. De esta manera, el periodo 2000-2006, además de contribuir a delinear las tendencias recientes, amplía las posibilidades analíticas al proveer información adicional a dicho nivel de desagregación.

En 2000-2006 destaca el liderazgo de la industria farmacéutica con una $\varepsilon$ de 4.7 (3521), seguida de instrumentos científicos y de precisión (385) con una $\varepsilon$ de 3.3, y productos automotrices (3841) con una $\varepsilon$ de 3.2. Un poco más abajo se ubican hierro y acero (371), y otro equipo de transporte (3842), ambos con valores de 2.9 ع. En todos los casos se trata de bienes para los que la demanda mundial crece a tasas por encima del promedio. Una observación interesante es que, salvo el 371, el resto coincide con los sectores clave identificados con los criterios 1 y 2 , sectores de tecnología alta o media-alta y difusores de conocimiento. Esto sugiere un puente entre la NTC y la TPK, que recomiendan la especialización hacia actividades de alta tecnología con fuertes efectos de derrame tecnológico, y con altas elasticidades ingreso, respectivamente.

Las actividades del sector servicios se clasificaron conforme a dos criterios: su intensidad en conocimientos y su vínculo con sectores de alta tecnología; no obstante, puesto que varias quedaron excluidas, el resto se agrupó bajo el concepto tradicionales. El cuadro 3 muestra esta clasificación, con un total de 11 actividades que cumplen con el primer criterio, tres con el segundo y siete con el tercero. Los servicios de comunicaciones, investigación y desarrollo, y los relacionados con la computación e informática, al cubrir los dos primeros criterios, se colocan como sectores clave, seguidos por algunos segmentos del transporte, el financiero, los servicios de alquiler, los de salud y asistencia social, los recreativos y culturales, así como los de carácter profesional, técnico y especializado, todos ellos caracterizados por su intensidad en el uso de conocimientos.

2 Véase McCombie y Thirlwall, 1994. 
Cuadro 2

Elasticidades ingreso de los grupos de productos con mayor participación en el comercio internacional (1990-2006)

\begin{tabular}{|l|c|c|c|c|c|}
\hline \multirow{2}{*}{ GRUPOS DE PRODUCTOS } & \multirow{2}{*}{ CÓDIGO CMAP } & \multicolumn{2}{c|}{ TAC exportaciones mundiales } & \multicolumn{2}{c|}{ Elasticidad ingreso } \\
\hline & & $1990-2006$ & $2000-2006$ & $1990-2006$ & $2000-2006$ \\
\hline PRODUCTOS AGRÍCOLAS & & 2.8 & 5.3 & 1.0 & 1.8 \\
\hline Alimentos & 111,130 & 3.1 & 5.7 & 1.1 & 1.9 \\
\hline Materias primas & 111,121 & 1.7 & 3.9 & 0.6 & 1.3 \\
\hline COMBUSTIBLES Y PRODUCTOS DE LA MINERIAA & & 4.5 & 6.7 & 1.6 & 2.2 \\
\hline Combustibles & 220 & 3.4 & 6.9 & 1.2 & 2.3 \\
\hline Productos de la minería & $210,231,232$ & 5.0 & 6.3 & 1.8 & 2.1 \\
\hline MANUFACTURAS & & 6.1 & 7.1 & 2.1 & 2.4 \\
\hline Hierro y acero & 371 & 5.1 & 8.6 & 1.8 & 2.9 \\
\hline Productos químicos & 351,352 & 6.0 & 7.8 & 2.1 & 2.6 \\
\hline Farmacéuticos & 3521 & N.D. & 14.10 & N.D. & 4.7 \\
\hline Otros productos químicos & 351,3522 & N.D. & 3.1 & N.D. & 1.0 \\
\hline Maquinaria y equipo de transporte & 382,383, & 8.0 & 8.5 & 2.8 & 2.8 \\
\hline Equipo de oficina y telecomunicaciones & 384,385 & & & & \\
\hline Equipo de transporte & 3823,3832 & 10.10 & 6.7 & 3.5 & 2.2 \\
\hline Productos automotrices & 3841 & N.D. & 8.8 & N.D. & 2.9 \\
\hline Otro equipo de transporte & 3841 & 7.2 & 9.5 & 2.5 & 3.2 \\
\hline Otra maquinaria & 3842 & N.D. & 8.6 & N.D. & 2.9 \\
\hline Textiles y prendas de vestir (321, 322) & 321,322 & 5.4 & 6.4 & 1.9 & 2.1 \\
\hline Textiles & 321 & 4.2 & 5.1 & 1.5 & 1.7 \\
\hline Prendas de vestir & 322 & 6.4 & 8.0 & 2.2 & 2.7 \\
\hline Otras manufacturas & 3240,3320, & N.D. & 6.0 & N.D. & 2.0 \\
\hline Bienes para uso personal y doméstico & 3560,3833 & & & & \\
\hline Instrumentos científicos y de precisión & 385 & N.D. & 9.8 & N.D. & 3.3 \\
\hline Manufacturas diversas & 390 & N.D. & 5.9 & N.D. & 2.0 \\
\hline TOTAL & & 6.9 & 8.5 & 2.4 & 2.8 \\
\hline
\end{tabular}

Nota: Las tasas de crecimiento del PIB mundial fueron $2.8 \%$ anual en el periodo $1990-2006$ y $3.0 \%$ en el periodo 2000-2006. Las exportaciones originalmente estaban expresadas en dólares corrientes, por lo que se deflactaron con un índice de precios de los Estados Unidos acorde al tipo de bienes.

Fuente: Elaboración propia con datos tomados de www.wto.org y de www.unescap.org 
Cuadro 3

Clasificación de las actividades de servicios

\begin{tabular}{|c|c|c|c|c|}
\hline SUBSECTORES & CÓDIGO CMAP & TRADICIONALES & $\begin{array}{l}\text { INTENSIVOS EN } \\
\text { CONOCIMIENTOS }\end{array}$ & $\begin{array}{c}\text { ALTA } \\
\text { TECNOLOGÍA }\end{array}$ \\
\hline Comercio al por mayor & $6110,6120,6140$ & $x$ & & \\
\hline Comercio al por menor & $\begin{array}{l}6210,6220,6230 \\
6240,6250,6260\end{array}$ & $x$ & & \\
\hline Transporte por agua & 7120 & & $X$ & \\
\hline Transporte por aire & 7130 & & $X$ & \\
\hline Transporte terrestre & $7111,7112,7113$ & $x$ & & \\
\hline Comunicaciones & 7200 & & $X$ & $x$ \\
\hline Servicios financieros y de seguros & $8110,8120,8130$ & & $x$ & \\
\hline $\begin{array}{l}\text { Servicios de alquiler y administración } \\
\text { de bienes inmuebles }\end{array}$ & 8211,8212 & $x$ & & \\
\hline Servicios de alquiler de bienes muebles & 8311,8312 & & $x$ & \\
\hline Servicios educativos & 9211,9212 & & $x$ & \\
\hline Servicios de investigación y desarrollo & 9221,9222 & & $x$ & $x$ \\
\hline Servicios de salud y asistencia social & $\begin{array}{l}9231,9232,9241 \\
9242,9250,9290\end{array}$ & & $X$ & \\
\hline Restaurantes y hoteles & 9310,9320 & $x$ & & \\
\hline $\begin{array}{l}\text { Servicios de esparcimiento, culturales } \\
\text { y deportivos }\end{array}$ & $\begin{array}{r}9411,9412,9421 \\
9422,9491,9492\end{array}$ & & $x$ & \\
\hline $\begin{array}{l}\text { Prestación de servicios profesionales, } \\
\text { técnicos, especializados y personales }\end{array}$ & $9510,9520,9530,9540$ & & & \\
\hline Servicios de reparación y mantenimiento & $9611,9612,9613$ & $x$ & & \\
\hline $\begin{array}{l}\text { Servicios a los sectores agropecuario, } \\
\text { construcción, transporte, financiero y comercio }\end{array}$ & $\begin{array}{l}9710,9720,9731,9732 \\
9733,9740,9750,9790\end{array}$ & $x$ & & \\
\hline $\begin{array}{l}\text { Servicios relacionados con software y equipo } \\
\text { de procesamiento informático* }\end{array}$ & & & $x$ & $x$ \\
\hline
\end{tabular}

*No disponible en la CMAP pero sí en el Sistema de Clasificación Industrial de América del Norte (CSIAN) con el código 5415.

Nota: La clasificación es una adaptación de la propuesta por el grupo de trabajo de Eurostat de la

Comunidad Económica Europea.

Fuente: datos tomados de Meri, 2008. 
Conviene hacer algunas precisiones en cuanto a las clasificaciones y los sectores clave identificados: primero, el nivel de agregación no permite una diferenciación por productos, lo cual puede generar sesgos si las actividades incluidas en un sector son heterogéneas con respecto a los criterios de selección; segundo, no se hace una distinción por procesos, lo que puede llevar erróneamente a considerar de alta tecnología o difusora de conocimientos a aquellas actividades que sólo desplazan a nuestro país sus fases de producción intensivas en trabajo. Éste es el caso de la industria maquiladora, que aun ubicándose en áreas de punta genera empleos de baja productividad y poco o nulo derrame de conocimientos. Por último, se debe señalar que se trata de aproximaciones basadas en la experiencia promedio a nivel internacional, o de grupos de países como los de la Organización para la Cooperación y el Desarrollo Económico (OECD) o la Comunidad Europea, en donde la composición y peso específico de las actividades, así como su nivel tecnológico puede discrepar en relación con nuestra estructura económica.

\section{Patrones de especialización y desempeño económico}

En este apartado se analiza la relación entre especialización y desempeño económico a través de dos ejercicios que utilizan información por estados. En el primero se calculan los coeficientes de correlación simple entre dos indicadores de desempeño (ingreso per cápita y su tasa de crecimiento) y los índices de especialización de cinco grandes agregados de actividades económicas: agropecuario, construcción, manufacturas, comercio y servicios. En el segundo se estima una ecuación de crecimiento de las utilizadas en los ejercicios de convergencia beta condicionada, introduciendo como variable condicionante el índice de especialización de los sectores clave.

\section{Análisis por actividades agregadas}

Se inicia con una clasificación de las entidades federativas por su nivel de ingresos (alto, medio, bajo) y por su ritmo de crecimiento (acelerado, medio, lento, decrecimiento), siguiendo criterios arbitrarios pero que generan rangos aceptables ${ }^{3}$. Por el

3 El nivel de ingresos se considera alto si $\mathbf{y}>\mathbf{y}_{\mathbf{N}}+0.9$ DE; medio si $\mathbf{y}$ se sitúa en el rango de $\mathbf{y}_{\mathbf{N}}$ \pm 0.9 DE y bajo si $\mathbf{y}<\mathbf{y}_{\mathbf{N}}-0.9$ DE. De igual manera se considera crecimiento acelerado si $\mathbf{g}>\mathbf{g}_{\mathbf{N}}$ +0.9 DE, crecimiento medio si $\mathbf{g}$ se sitúa en $\mathbf{g}_{\mathbf{N}} \pm 0.9 \mathrm{DE}$, crecimiento lento si $\mathbf{g}<\mathbf{g}_{\mathbf{N}}-0.9$ DE y decrecimiento si $\mathbf{g}<0$. Los símbolos $\mathbf{y}$, $\mathbf{g}$ se refieren al PIB per cápita y a su tasa de crecimiento anual, mientras que el subíndice $\mathrm{N}$ y DE significan, respectivamente, promedio nacional y desviación estándar. Estos rangos se definieron mediante ejercicios de ensayo y error tratando de obtener un número reducido de entidades en los valores extremos y la concentración mayoritaria en el valor medio.

Vol. 40, núm. 159, octubre-diciembre / 2009 
lado de los ingresos, el ejercicio muestra cinco entidades en el nivel alto, 20 en el medio y siete en el bajo; con respecto al ritmo de crecimiento, se sitúan seis en acelerado, 20 en medio, cinco en lento y una en decrecimiento. La brecha entre los grupos extremos alcanza una razón de 3.3 veces en el primer caso y 4.8 en el segundo si se excluye Quintana Roo, la única entidad que registra decrecimiento. Si la comparación se hace entre las entidades situadas en los extremos, las razones anteriores se modifican a 6 y 9.3, respectivamente. Estas cifras ilustran la polarización regional y la heterogeneidad del proceso de desarrollo que han caracterizado al país y que se han agudizado por lo menos desde mediados de la década de 1980 (véase cuadro 4).

¿En qué medida la brecha de ingreso y la divergencia en tasas de crecimiento se explica por los tipos de especialización? Una exploración sencilla a través de correlaciones simples entre ingreso per cápita e IE muestra una asociación negativa en las actividades agropecuarias y de construcción, y positiva en los servicios, comercio y manufacturas. Por la magnitud de los coeficientes se puede inferir que mayores ingresos se relacionan preponderantemente con una contracción relativa del agro y una terciarización de la economía. Algo distinto ocurre con el proceso de crecimiento económico, en el que la industrialización parece jugar un papel central como fuerza impulsora, mientras que la especialización en los servicios aparentemente actúa en sentido contrario (véase cuadro 5).

Si se relacionan los IE con las agrupaciones de entidades por nivel de ingresos, se observan los siguientes patrones: primero, el tamaño relativo del sector agropecuario es inversamente proporcional al grado de riqueza, lo cual es consistente con la baja productividad de estas actividades y con la presencia de rendimientos decrecientes en su función producción. Segundo, las actividades de la construcción y el comercio no muestran un patrón definido que indique una función importante y sistemática en el proceso de desarrollo. Tercero, tanto las manufacturas como los servicios tienden a ganar peso relativo a medida que se transita hacia estratos de ingresos más altos, aunque esta relación se encuentra mediada por la composición sectorial, y es más fuerte mientras mayor es la concentración de actividades modernas. Un ejercicio similar pero considerando los grupos de estados por tipo de crecimiento sugiere que un crecimiento lento se asocia a un sector agropecuario grande y una industria pequeña en términos relativos, mientras que un crecimiento acelerado se relaciona con la combinación inversa. Al igual que en el caso anterior, la construcción y el comercio no muestran un vínculo claro respecto del buen desempeño de la economía. En lo que se refiere a los servicios, los datos indican que la especialización suele asociarse a una desaceleración del crecimiento (véase cuadro 6). 
Cuadro 4

Clasificación de las entidades por nivel de ingresos y tipo de crecimiento

\begin{tabular}{|c|c|c|c|c|}
\hline Entidades & $\begin{array}{l}\text { Ingreso per cápita } 2006 \\
\text { (pesos de 1993) }\end{array}$ & Nivel & $\begin{array}{c}\text { TCA } \\
1993-2006\end{array}$ & Tipo \\
\hline Aguascalientes & 20499 & Medio & 2.9 & Acelerado \\
\hline Baja California & 19931 & Medio & 1.3 & Medio \\
\hline Baja California Sur & 19673 & Medio & 0.9 & Medio \\
\hline Campeche & 23859 & Alto & 0.3 & Lento \\
\hline Coahuila & 23013 & Alto & 2.8 & Acelerado \\
\hline Colima & 16126 & Medio & 1.2 & Medio \\
\hline Chiapas & 6576 & Bajo & 0.7 & Lento \\
\hline Chihuahua & 23745 & Alto & 2.6 & Acelerado \\
\hline Distrito Federal & 39280 & Alto & 1.4 & Medio \\
\hline Durango & 14809 & Medio & 2.5 & Acelerado \\
\hline Guanajuato & 12798 & Medio & 2.6 & Acelerado \\
\hline Guerrero & 8351 & Bajo & 0.6 & Lento \\
\hline Hidalgo & 9552 & Bajo & 0.7 & Lento \\
\hline Jalisco & 15474 & Medio & 1.2 & Medio \\
\hline México & 12676 & Medio & 1.1 & Medio \\
\hline Michoacán & 9521 & Bajo & 2.1 & Medio \\
\hline Morelos & 14908 & Medio & 1.1 & Medio \\
\hline Nayarit & 9910 & Medio & 0.9 & Medio \\
\hline Nuevo Léon & 29453 & Alto & 2.3 & Medio \\
\hline Oaxaca & 6845 & Bajo & 0.9 & Medio \\
\hline Puebla & 11058 & Medio & 2.0 & Medio \\
\hline Querétaro & 18720 & Medio & 2.3 & Medio \\
\hline Quintana Roo & 21108 & Medio & -1.1 & Decrecimiento \\
\hline San Luis Potosí & 13081 & Medio & 2.4 & Acelerado \\
\hline Sinaloa & 13219 & Medio & 1.1 & Medio \\
\hline Sonora & 20502 & Medio & 2.2 & Medio \\
\hline Tabasco & 9546 & Bajo & 0.4 & Lento \\
\hline Tamaulipas & 17406 & Medio & 2.1 & Medio \\
\hline Tlaxcala & 8285 & Bajo & 1.3 & Medio \\
\hline Veracruz & 9769 & Medio & 1.5 & Medio \\
\hline Yucatán & 12898 & Medio & 1.8 & Medio \\
\hline Zacatecas & 9966 & Medio & 2.3 & Medio \\
\hline Nacional & 16186 & & 1.5 & \\
\hline
\end{tabular}

Fuente: Elaboración propia con datos tomados de INEGI. 
Cuadro 5

Indicadores de desempeño e índices de especialización (coeficientes de correlación)

\begin{tabular}{|l|c|c|c|c|c|}
\hline Grupos & Agropecuario & Construcción & Manufacturas & Comercio & Servicios \\
\hline Ingresos & -0.838 & -0.097 & 0.208 & 0.229 & 0.675 \\
\hline Crecimiento & -0.194 & -0.049 & 0.693 & 0.272 & -0.290 \\
\hline
\end{tabular}

Nota: La variable ingresos corresponde al PIB per cápita. Los índices de especialización utilizados se calcularon con datos de la ENOE 2007, que publica INEGI.

Fuente: Elaboración propia.

\section{Cuadro 6}

Índices de especialización (promedios)

\begin{tabular}{|l|c|c|c|c|c|}
\hline & Agropecuario & Construcción & Manufacturas & Comercio & Servicios \\
\hline Ingresos altos & -0.434 & -0.043 & 0.034 & -0.024 & 0.044 \\
\hline Ingresos medios & -0.064 & 0.037 & -0.069 & 0.000 & -0.003 \\
\hline Ingresos bajos & 0.269 & -0.025 & -0.141 & -0.058 & -0.080 \\
\hline Crecimiento acelerado & -0.109 & -0.026 & 0.110 & -0.010 & -0.041 \\
\hline Crecimiento medio & -0.097 & 0.028 & -0.061 & -0.005 & -0.004 \\
\hline Crecimiento lento $^{\star}$ & 0.172 & -0.010 & -0.271 & -0.062 & -0.010 \\
\hline
\end{tabular}

Nota: *Incluye entidades que tuvieron decrecimiento. Números positivos indican especialización y números negativos desespecialización. El índice de especialización se construye con los datos del empleo tomados de la ENOE, 2007.

Fuente: Elaboración propia.

Lo anterior permite ubicar a las entidades federativas de México de acuerdo con su nivel de desarrollo en tres grandes grupos: el primero, conformado por los estados en donde el tamaño del sector primario es aún grande, se caracteriza por los bajos ingresos de su población y la lentitud del crecimiento económico, lo que ocasiona desocupación y pobreza; el segundo, que aglutina a entidades de ingresos medios y altos en donde la industrialización avanza firmemente, se distingue por sus altas tasas de crecimiento y el dinamismo del empleo y las oportunidades de negocios, lo que hace de este segmento el motor de la economía nacional; el tercero reúne a los estados cuya economía está regida por el sector servicios, ya sea porque la expansión industrial ha entrado en una fase de agotamiento o porque la estructura de ventajas comparativas y competitivas regionales ha favorecido dicha situación. Cualquiera que sea el caso, se trata de economías de ingresos medios y altos, con un dinamismo inferior a las del segundo grupo. 
El impacto de los sectores clave

\section{-Aspectos metodológicos}

Con la finalidad de evaluar la contribución de los sectores clave al crecimiento económico de los estados durante el periodo 1988-2003, se estima una ecuación de crecimiento que puede ser derivada de una función de producción Cobb-Douglas del tipo $\mathrm{Y}=\mathrm{AK}^{\alpha} \mathrm{L}^{\beta}$, en donde la magnitud de los rendimientos a escala $(\alpha+\beta)$ es una cuestión empírica. La especificación utilizada para realizar la estimación incluye dos variables adicionales: $\mathrm{IE}_{\mathrm{i}}$, que captura el impacto de la especialización en sectores clave sobre la tasa de crecimiento de la producción, el cual se asocia a cambios en la tecnología (A) resultantes de la reasignación de recursos hacia actividades con rendimientos crecientes a escala, y $\mathrm{VAB}_{0} / \mathrm{L}_{0}$, que cuantifica el efecto emparejamiento tecnológico o catch up, es decir, la parte del crecimiento económico atribuible a la adopción de la tecnología disponible en los países o regiones líderes y que permite acelerar transitoriamente la tasa de crecimiento. Esto supone que $\mathrm{g}_{\mathrm{A}}$, en este caso la tasa de progreso técnico, es afectada por un componente exógeno $(\mathrm{C})$, por la reasignación de recursos hacia sectores con condiciones especiales $\left(\mathrm{IE}_{\mathrm{i}}\right)$ y por el grado de atraso de la tecnología empleada medido con un indicador de productividad correspondiente al año inicial del periodo analizado $\left(\mathrm{VAB}_{0} / \mathrm{L}_{0}\right): \mathrm{g}_{\mathrm{A}}=\mathrm{F}\left(\mathrm{C}, \mathrm{IE}_{\mathrm{i}}, \mathrm{VAB}_{0} / \mathrm{L}_{0}\right)$. En consecuencia, se propone la siguiente especificación empírica:

$$
\mathbf{g}_{\mathrm{VABj}}=\mathbf{C}+\alpha \mathbf{g}_{\mathrm{AFj}}+\beta \mathbf{g}_{\mathrm{Lj}}+\theta \mathbf{I E}_{\mathrm{i}, \mathrm{j}}+\rho \ln \left(\mathbf{V A B} \mathbf{B}_{\mathbf{0}} / \mathbf{E}_{\mathbf{0}}\right)_{\mathbf{j}}+\mathbf{u}_{\mathbf{j}}
$$

Los términos $\mathrm{VAB}, \mathrm{AF}$ y $\mathrm{L}$ hacen referencia, respectivamente, al valor agregado bruto, al valor de los activos fijos y al personal ocupado; la letra g indica que se trata de una tasa de crecimiento anual; los subíndices $\mathbf{j}$ e i se refieren a la entidad y al sector productivo, que en este caso se define de acuerdo con la CMAP, y uj es un término de error cuyo valor esperado es cero y que cumple con las propiedades típicas de no autocorrelación, homocedasticidad y normalidad. Tanto VAB como AF y L corresponden a una agregación de las actividades industriales, comerciales y de servicios, por lo que se trata de una aproximación del desempeño económico general de las entidades federativas; sólo falta incluir las actividades primarias. La variable $\mathrm{IE}_{\mathrm{i}}$ se obtuvo como $\left[\left(\mathrm{L}_{\mathrm{i}, \mathrm{j}} / \mathrm{L}_{\mathrm{j}}\right) /\left(\mathrm{L}_{\mathrm{i}, \mathrm{N}} / \mathrm{L}_{\mathrm{N}}\right)-1 /\left(\mathrm{L}_{\mathrm{i}, \mathrm{j}} / \mathrm{L}_{\mathrm{j}}\right) /\left(\mathrm{L}_{\mathrm{i}, \mathrm{N}} / \mathrm{L}_{\mathrm{N}}\right)+1\right]^{4}$, lo que permite distinguir entre procesos de especialización y desespecialización por su signo positivo o negativo. Los datos dispo-

$4 \quad$ El subíndice indica que se trata de una variable nacional.

Vol. 40, núm. 159, octubre-diciembre / 2009 
nibles permitieron la construcción del $\mathrm{IE}_{\mathrm{i}}$ para 23 sectores clave: 12 de la manufactura y 11 de los servicios. La información corresponde al periodo 1988-2003 y fue obtenida de los Censos Económicos 1989, 1994 y 2004 realizándose una deflactación en todas aquellas variables expresadas en términos monetarios.

De acuerdo con la teoría se esperan signos positivos para $\alpha$ y $\beta$, y negativo para $\rho$. El signo de $\theta$ es una cuestión empírica y depende de que el sector contribuya a acelerar la tasa de crecimiento. Una reasignación de recursos hacia sectores de baja productividad podría desacelerarla, mientras que lo contrario ocurriría si éstos se orientaran hacia sectores más productivos. La especialización sectorial puede modificar los rendimientos a escala del conjunto de la economía y por tanto alterar los valores y significancia estadística de $\alpha$ y $\beta$. Así, cuando se compara la función 1 con y sin la variable $\mathrm{IE}_{\mathrm{i}}$, si $\theta$ es positivo y estadísticamente significativo y además la suma $\alpha+\beta$ aumenta con la inclusión de $\mathrm{IE}_{\mathrm{i}}$, se considera que la reasignación de recursos hacia el sector i tiene efectos positivos sobre el desempeño general de la economía.

La estimación se realiza a través de un ejercicio de corte transversal en donde cada entidad federativa representa una observación. Se recurre a la técnica de mínimos cuadrados con errores estándar y covarianzas ajustadas por el método de White, lo cual permite que éstos sean consistentes en presencia de heteroscedasticidad. Aunque el reducido número de observaciones es una limitante (32 observaciones), se elige este método en lugar de una técnica de datos de panel que hubiera ampliado la muestra debido a que ejercicios realizados considerando los subperiodos 1988-1993, 1993-1998 y 1998-2003 arrojaron coeficientes poco razonables tanto en magnitud como en signo. Ello se explica por lo corto de los subperiodos, que no permite la manifestación plena de un fenómeno que es esencialmente de largo plazo. También influyen los cambios atípicos en las magnitudes de algunas variables atribuibles a fenómenos coyunturales, cuyo efecto tiende a diluirse en un periodo más largo.

\section{- Análisis de resultados}

Los resultados econométricos indican que en términos generales la especialización en actividades clave tiene una impacto positivo sobre la tasa de crecimiento económico, aunque ello no necesariamente signifique que contribuya a elevar los rendimientos a escala de la función de produción agregada de las entidades federativas, lo cual sólo ocurre en casos muy específicos. Por otra parte, se observa que tanto $\mathrm{C}$ como $\rho$ tienen los signos correctos y son estadísticamente significativos, mostrando poca sensibilidad a la inclusión de los $\mathrm{IE}_{\mathrm{i}}$ dentro de la función estimada. Sus valores fluctúan entre 0.57 y 0.66 en el caso de $C$, y entre -0.05 y -0.06 en el caso de $\rho$. 
De acuerdo con la regresión 1, la función agregada muestra rendimientos constantes a escala ( $\alpha+\beta$ se aproxima a la unidad), y no se registran variaciones importantes cuando se introducen $\mathrm{IE}_{\mathrm{i}}$ a nivel de grandes agregados de actividades (agropecuario, manufacturas, construcción, comercio y servicios) ${ }^{5}$. De igual manera, los valores de $\theta$, con excepción del correspondiente al sector agropecuario, que además tiene signo negativo, no son significativos, sugiriendo que el efecto de la especialización sobre el crecimiento es más específico y asociado a actividades concretas. Una desagregación de la industria manufacturera por divisiones de actividad económica muestra tres grupos con características claramente diferenciadas: el primero, integrado por industrias en donde la especialización no parece tener una función importante sobre el desempeño económico, agrupa a las divisiones 32, 33, 36 y 39; el segundo, compuesto por industrias en donde especializarse conlleva a una reducción de la tasa de crecimiento, incluye a la división 31; y el tercero, en donde hay una relación clara entre especialización y crecimiento, aglutina a las divisiones 34, 35, 37 y 38 (véase cuadro 7).

Los valores negativos y significativos de $\theta$ encontrados tanto en el sector agropecuario como en la división 31 de las manufacturas que comprende la industria de alimentos, bebidas y tabaco, ilustran las desventajas asociadas a un patrón de especialización dirigido por actividades intensivas en recursos naturales y cuestiona el argumento que promueve una especialización espontánea basada en las ventajas comparativas estáticas, determinadas por las dotaciones iniciales de recursos de cada economía. Asimismo, los valores positivos de $\theta$ para el tercer grupo de actividades y el incremento asociado en los rendimientos a escala de la función de producción agregada muestran las ventajas de una especialización dirigida, orientada a desarrollar actividades con características especiales, particularmente aquéllas con capacidad para acelerar el crecimiento de la productividad.

La diversidad que se observa en la relación entre especialización y crecimiento dentro de la industria manufacturera, muestra la heterogeneidad que caracteriza a la estructura productiva nacional, compuesta por segmentos tradicionales, de tecnología intermedia y modernos. La distribución desigual de estos segmentos a lo largo del país determina que la industrialización tenga efectos regionales diferenciados, y que las tasas de crecimiento que se alcanzan en cada estado dependan no sólo del tamaño relativo del sector manufacturero dentro del conjunto de la economía, sino también y sobre todo de su composición por tipo de actividades.

$5 \quad$ Véanse regresiones 2 a 6 en el cuadro 7.

Vol. 40, núm. 159, octubre-diciembre / 2009 
Cuadro 7

Resumen de resultados econométricos (estimación de la ecuación 1)

Variable dependiente: tasa de crecimiento del VAB de los estados (gVAB), 1988-2003

\begin{tabular}{|c|c|c|c|c|c|c|c|c|c|}
\hline \begin{tabular}{|c|} 
Número \\
de regresión
\end{tabular} & $\begin{array}{l}\text { Indice de especialización } \\
\text { (IE) utilizado en la regresión }\end{array}$ & $\begin{array}{l}\text { Constante } \\
\text { (C) }\end{array}$ & $\begin{array}{l}g_{\text {AF }} \\
(\alpha)\end{array}$ & $\begin{array}{l}g_{E} \\
(\beta)\end{array}$ & $\begin{array}{c}\ln V_{a b} / L_{0} \\
(\rho)\end{array}$ & $\begin{array}{l}I_{E_{i}} \\
(\theta)\end{array}$ & $R^{2} a j$ & $D W$ & $F$ \\
\hline 1 & & $0.60(8.29)$ & $0.20(1.70)$ & $0.76(1.44)$ & $-0.06(-7.98)$ & & 0.89 & 2.12 & 79.21 \\
\hline 2 & Agropecuario & $0.62(7.51)$ & $0.16(1.28)$ & $0.87(2.70)$ & $-0.06(-7.58)$ & $-0.03(2.53)$ & 0.92 & 2.21 & 86.52 \\
\hline 3 & Manufacturas & $0.61(8.26)$ & $0.22(1.81)$ & $0.78(1.43)$ & $-0.06(-7.91)$ & $0.02(1.26)$ & 0.89 & 2.20 & 59.43 \\
\hline 4 & Construcción & $0.59(8.39)$ & $0.17(1.65)$ & $0.91(1.93)$ & $-0.06(-8.03)$ & $-0.03(-0.66)$ & 0.89 & 2.11 & 58.27 \\
\hline 5 & Comercio & $0.59(7.75)$ & $0.21(1.82)$ & $0.79(1.56)$ & $-0.05(-7.51)$ & $0.06(1.01)$ & 0.89 & 1.95 & 59.20 \\
\hline 6 & Servicios & $0.59(7.51)$ & $0.17(1.37)$ & $0.81(1.86)$ & $\cdot 0.05(-7.49)$ & $0.05(0.94)$ & 0.89 & 2.16 & 61.80 \\
\hline 7 & Subsector 31 & $0.61(8.19)$ & $0.09(0.87)$ & $0.60(2.75)$ & $-0.06(-8.27)$ & $-0.08(-4.57)$ & 0.94 & 2.12 & 78.17 \\
\hline 8 & Subsector 32 & $0.59(7.58)$ & $0.19(1.64)$ & $0.77(1.45)$ & $-0.05(-7.49)$ & $-0.01(-0.83)$ & 0.89 & 2.12 & 58.63 \\
\hline 9 & Subsector 33 & $0.62(7.81)$ & $0.17(1.43)$ & $0.80(1.67)$ & $-0.06(7.65)$ & $-0.02(-1.60)$ & 0.89 & 1.78 & 62.31 \\
\hline 10 & Subsector 34 & $0.62(9.31)$ & $0.22(2.14)$ & $0.94(2.46)$ & $-0.06(-9.30)$ & $0.04(3.37)$ & 0.92 & 2.43 & 83.14 \\
\hline 11 & Subsector 35 & $0.68(8.70)$ & $0.23(2.09)$ & $0.85(1.97)$ & $-0.06(-8.70)$ & $0.03(3.33)$ & 0.91 & 1.86 & 76.64 \\
\hline 12 & Subsector 36 & $0.57(7.26)$ & $0.17(1.55)$ & $0.87(1.79)$ & $-0.05(-7.02)$ & $-0.01(-0.90)$ & 0.89 & 2.14 & 59.64 \\
\hline 13 & Subsector 37 & $0.59(8.98)$ & $0.26(2.09)$ & $0.88(1.64)$ & $-0.06(-8.99)$ & $0.01(2.03)$ & 0.90 & 2.03 & 63.16 \\
\hline 14 & Subsector 38 & $0.63(7.19)$ & $0.24(1.84)$ & $0.85(1.53)$ & $\cdot 0.06(-7.09)$ & $0.02(2.52)$ & 0.89 & 2.02 & 44.00 \\
\hline 15 & Subsector 39 & $0.60(8.16)$ & $0.20(1.64)$ & $0.77(1.44)$ & $-0.06(-7.83)$ & $0.00(0.27)$ & 0.89 & 2.14 & 57.30 \\
\hline 16 & Sectores estratégicos & $0.65(9.36)$ & $0.21(2.19)$ & $0.87(2.37)$ & $-0.06(-9.42)$ & $0.04(3.78)$ & 0.93 & 2.39 & 94.29 \\
\hline 17 & Manufacturas estratégicas & $0.64(7.53)$ & $0.23(2.03)$ & $0.91(1.73)$ & $-0.06(-7.45)$ & $0.02(3.12)$ & 0.90 & 2.05 & 46.98 \\
\hline 18 & Servicios estratégicos & $0.66(10.54)$ & $0.21(2.18)$ & $0.93(2.07)$ & $-0.06(-10.58)$ & $0.07(4.01)$ & 0.93 & 2.20 & 93.85 \\
\hline 19 & Sectores con altas elasticidades ingreso & $0.62(8.71)$ & $0.24(1.95)$ & $0.88(1.73)$ & $-0.06(-8.44)$ & $0.02(2.79)$ & 0.90 & 2.42 & 69.75 \\
\hline 20 & Sectores difusores de conocimientos & $0.63(7.58)$ & $0.21(1.86)$ & $0.97(2.05)$ & $-0.06(-7.50)$ & $0.03(2.52)$ & 0.91 & 2.01 & 50.79 \\
\hline 21 & Sectores de alta tecnología* & $0.64(7.37)$ & $0.22(1.89)$ & $0.97(2.14)$ & $-0.06(7.36)$ & $0.03(2.56)$ & 0.91 & 2.01 & 51.21 \\
\hline 22 & Productos farmacéuticos & $0.63(7.42)$ & $0.19(1.71)$ & $0.81(1.81)$ & $-0.06(-7.43)$ & $0.01(1.22)$ & 0.89 & 2.02 & 62.28 \\
\hline 23 & Otros productos químicos & $0.62(6.33)$ & $0.19(1.57)$ & $0.78(1.57)$ & $-0.06(6.35)$ & $0.00(0.46)$ & 0.89 & 2.09 & 57.72 \\
\hline 24 & Productos químicos industriales & $0.62(7.89)$ & $0.23(1.91)$ & $0.82(1.61)$ & $-0.06(-7.86)$ & $0.01(2.10)$ & 0.90 & 1.95 & 64.13 \\
\hline 25 & Hierro y acero & $0.60(8.61)$ & $0.24(1.91)$ & $0.79(1.45)$ & $-0.06(-8.46)$ & $0.01(1.21)$ & 0.89 & 2.06 & 59.45 \\
\hline 26 & Equipo electrónico y de comunicaciones & $0.60(8.27)$ & $0.21(1.76)$ & $0.78(1.41)$ & $-0.06(7.85)$ & $0.01(2.20)$ & 0.89 & 2.39 & 67.45 \\
\hline 27 & Productos metálicos, excepto maquinaria y equipo & $0.63(7.94)$ & $0.20(1.61)$ & $0.78(1.39)$ & $-0.06(-7.44)$ & $0.02(1.40)$ & 0.89 & 2.17 & 59.73 \\
\hline 28 & Industria automotriz & $0.63(7.46)$ & $0.21(1.76)$ & $0.79(1.39)$ & $-0.06(-7.16)$ & $0.01(2.38)$ & 0.89 & 2.05 & 41.51 \\
\hline 29 & $\begin{array}{l}\text { Equipo de transporte y sus partes, } \\
\text { excepto automóviles y camiones }\end{array}$ & $0.60(8.17)$ & $0.20(1.67)$ & $0.79(1.39)$ & $-0.06(-7.83)$ & $0.00(0.46)$ & 0.89 & 2.16 & 57.40 \\
\hline 30 & Instrumentos y equipo de precisión & $0.62(8.03)$ & $0.20(2.32)$ & $0.89(2.09)$ & $-0.06(-7.72)$ & $0.02(3.26)$ & 0.91 & 2.00 & 52.10 \\
\hline 31 & Maquinaria diversa & $0.67(8.26)$ & $0.21(1.69)$ & $0.88(1.59)$ & $-0.06(-7.98)$ & $0.01(2.30)$ & 0.90 & 2.30 & 64.81 \\
\hline 32 & Maquinaria, equipo y accesorios eléctricos & $0.63(7.36)$ & $0.22(1.90)$ & $0.83(1.70)$ & $-0.06(-7.24)$ & $0.02(2.77)$ & 0.90 & 2.00 & 46.90 \\
\hline 33 & $\begin{array}{l}\text { Máquinas de oficina, cálculo } \\
\text { y procesamiento informático }\end{array}$ & $0.59(8.44)$ & $0.21(1.72)$ & $0.84(1.49)$ & $-0.05(-8.06)$ & $0.01(2.04)$ & 0.89 & 2.27 & 62.45 \\
\hline 34 & Servicios de transporte por agua & $0.60(7.67)$ & $0.20(1.68)$ & $0.75(1.43)$ & $-0.06(-7.21)$ & $0.00(0.29)$ & 0.89 & 2.10 & 57.32 \\
\hline 35 & Servicios de transporte por aire & $0.58(8.44)$ & $0.14(1.21)$ & $0.86(2.08)$ & $-0.05(-8.09)$ & $0.02(1.20)$ & 0.90 & 1.98 & 63.35 \\
\hline 36 & Servicios de comunicaciones & $0.59(8.05)$ & $0.17(1.72)$ & $0.85(1.94)$ & $-0.06(-7.51)$ & $0.01(0.520$ & 0.89 & 2.07 & 58.20 \\
\hline 37 & Servicios financieros y de seguros & $0.61(8.32)$ & $0.15(1.45)$ & $1.02(2.55)$ & $-0.06(-8.18)$ & $0.02(2.55)$ & 0.91 & 1.97 & 71.26 \\
\hline 38 & Servicios de alquiler de bienes muebles & $0.60(8.24)$ & $0.19(1.59)$ & $0.83(1.56)$ & $-0.06(-7.97)$ & $-0.01(-0.47)$ & 0.89 & 2.13 & 57.55 \\
\hline 39 & Servicios educativos & $0.62(7.730$ & $0.20(1.77)$ & $0.74(1.45)$ & $-0.06(-7.74)$ & $0.02(0.860$ & 0.89 & 1.96 & 58.69 \\
\hline 40 & Servicios de investigación y desarrollo & $0.66(10.25)$ & $0.09(0.98)$ & $1.14(2.96)$ & $-0.06(-10.00)$ & $0.03(2.73)$ & 0.92 & 2.24 & 79.65 \\
\hline 41 & Servicios de salud y asistencia social & $0.60(6.98)$ & $0.20(1.59)$ & $0.67(1.37)$ & $-0.05(-6.78)$ & $-0.06(-1.79)$ & 0.89 & 1.99 & 43.47 \\
\hline 42 & $\begin{array}{l}\text { Servicios de esparcimiento, } \\
\text { culturales y deportivos }\end{array}$ & $0.59(8.84)$ & $0.23(1.96)$ & $0.84(1.64)$ & $-0.06(-8.18)$ & $-0.03(-2.02)$ & 0.89 & 2.27 & 61.82 \\
\hline 43 & $\begin{array}{l}\text { Servicios profesionales, técnicos, } \\
\text { especializados y personales }\end{array}$ & $0.63(10.02)$ & $0.13(1.43)$ & $0.97(3.27)$ & $-0.06(-9.81)$ & $0.08(3.87)$ & 0.92 & 1.88 & 89.33 \\
\hline 44 & $\begin{array}{l}\text { Servicios relacionados con soffware y } \\
\text { equipo de procesamiento informático }\end{array}$ & $0.63(9.00)$ & $0.15(1.35)$ & $1.01(2.75)$ & $-0.06(-8.62)$ & $0.02(2.44)$ & 0.92 & 2.16 & 80.80 \\
\hline
\end{tabular}

Nota 1: El concepto sector estratégico se emplea como sinónimo de sector clave.

Nota 2: Los datos utilizados para construir la variable IE en las regresiones 2 a 6 proceden de la ENOE, mientras que en las regresiones 7 a 44 provienen de los Censos Económicos. En ambos casos la fuente es INEGI.

Nota 3: Las regresiones incluyen una variable dicotómica para controlar el efecto de los estados petroleros (Campeche y Tabasco).

*Incluye a los sectores clasificados como de tecnología media-alta.

Fuente: Elaboración propia, con datos del INEGI.

\section{Desarrollo}


Un segundo nivel de análisis se realiza respecto de seis agrupaciones (regresiones 16 a 21): grupo 1, sectores estratégicos, incluye los 23 sectores clave que se consideran en el análisis empírico de este trabajo; grupo 2, manufacturas estratégicas, aglutina a 12 de esos sectores; grupo 3, servicios estratégicos, reúne 11 sectores; grupo 4, actividades con altas elasticidades ingreso, integrado por nueve sectores, todas ellos manufactureros; grupo 5, actividades difusoras de conocimientos, con 12 sectores; y grupo 6, actividades de alta tecnología, con 13 sectores. Los últimos dos grupos corresponden a combinaciones de manufacturas y servicios. Como puede apreciarse, las clasificaciones no son excluyentes. En todos los casos, la inclusión del indicador correspondiente de $\mathrm{IE}_{\mathrm{i}}$ impacta positivamente el crecimiento y eleva los rendimientos a escala, lo que hace evidente su importancia para el desarrollo económico, no sólo porque acelera la expansión del producto, sino porque debido al mayor dinamismo de la productividad pueden contribuir a elevar los ingresos de la población.

La desagregación a tres y cuatro dígitos de la CMAP (regresiones 22 a 44) corrobora la importancia del subsector 38 , particularmente de las ramas de instrumentos y equipo de precisión; maquinaria diversa; maquinaria, equipo y accesorios eléctricos; y máquinas de oficina, cálculo y procesamiento informático. En todas ellas se comprueba que la especialización promueve el crecimiento e incrementa los rendimientos a escala en la producción agregada. Un comportamiento similar se observa en la industria química y en algunos servicios como los de investigación y desarrollo, profesionales y técnicos, financieros y relacionados con software y procesamiento informático. En el resto de los sectores se observa una o más de las siguientes situaciones: no se encontró significancia estadística para el parámetro $\theta ; \theta$ tiene signo negativo o no se observa que el sector contribuya a romper el patrón de rendimientos constantes a escala en la producción global de los estados.

\section{Reflexiones finales}

Los resultados de este trabajo muestran una relación robusta entre crecimiento y especialización cuando ésta se orienta hacia sectores con características especiales, a los que denominamos sectores clave. No obstante, la contribución de éstos no es homogénea: se distinguen claramente actividades con mayor potencial para aumentar los rendimientos a escala de la función de producción agregada y, por tanto, para acelerar la tasa de crecimiento. De igual manera, se identifican actividades que teóricamente deberían tener una contribución importante al desempeño económico, lo cual no sucede en los hechos; una posible explicación es la heterogeneidad de la composición sectorial que determina la coexistencia de segmentos de alta o media-

Vol. 40, núm. 159, octubre-diciembre / 2009 
alta tecnología con segmentos tradicionales al interior de un mismo sector. También es posible que en algunos casos se trate de actividades modernas que sólo desplazan a nuestro país los procesos intensivos en mano de obra, como es el caso de la industria maquiladora, lo que inhibe los efectos de derrame tecnológico y el impacto sobre la productividad.

El papel de las actividades clave como fuente de diferencias en el desempeño económico de los estados de México se corrobora independientemente de los criterios utilizados para seleccionarlas; en la mayoría de los casos se ha hallado una aportación favorable al crecimiento. Llama la atención la frecuencia con que dichas actividades coinciden; por ejemplo, la mayoría de los bienes con altas elasticidades ingreso pertenecen a la categoría de difusores de conocimientos o alta tecnología, que a su vez se asocian a industrias intensivas en capital humano y con altas tasas de progreso técnico. La implicación es simple: es posible tender puentes entre teorías aparentemente irreconciliables como la NTC y la TPK, tal como lo sugieren Dalum, Laursen y Verspagen (1999), pero además ambas proporcionan una buena guía para orientar la especialización e impulsar el desarrollo.

La experiencia nacional muestra que las regiones ricas son predominantemente economías de servicios; las que más crecen se especializan en la producción de manufacturas y suelen ser de ingresos medios y altos; mientras que las pobres orientan sus procesos productivos hacia actividades intensivas en recursos naturales. El crecimiento parece mantener una asociación negativa con los procesos de primarización y terciarización de las economías, aunque la magnitud e incluso el signo de la relación puede variar dependiendo de la composición sectorial. Esto es especialmente cierto en economías de servicios, en las que una alta participación de sectores clave puede reportar beneficios tangibles en este sentido.

En suma, se puede concluir que el tipo de actividades que realiza una comunidad y la clase de bienes que produce son de la mayor importancia para determinar su desempeño económico. Éste se ve favorecido cuando se expanden las que enfrentan demandas dinámicas, las de mayores efectos multiplicadores, las que más impactan la productividad y las que generan los empleos cualitativamente mejores. Existen argumentos teóricos y empíricos suficientes para sostener que son las actividades modernas, principalmente las manufactureras y algunos servicios, las que ofrecen mejores condiciones, y que las ramas tradicionales, independientemente del sector en que se ubiquen, son las que menos contribuyen. Sin embargo, no se debe subestimar la aportación que éstas tienen al crecimiento, sobre todo si se considera su elevada participación en la composición industrial del país. 


\section{Bibliografía}

Arroyo, Francisco, "Dinámica del PIB de las entidades federativas de México, 1980-1999", Comercio exterior, vol. 51, núm. 7, México, Bancomext, julio de 2001, pp. 583-599.

Calderón, Cuauhtémoc y Gerardo Martínez, "La ley de Verdoom y la industria manufacturera regional en México en la era del TLCAN", Frontera norte, vol. 17, núm. 34 Tijuana, El Colegio de la Frontera Norte, julio-diciembre de 2005, pp. 103-137.

Calderón, Cuauhtémoc y Anna Tykhonenko, "Convergencia regional e inversión extranjera directa en México en el contexto del TLCAN, 1994-2002", Investigación económica, vol. LXVI, núm. 259, México, Facultad de Economía-UNAM, enero-marzo de 2007, pp. 15-41.

Cimoli, Mario et al., "Cambio estructural, heterogeneidad productiva y tecnología en América Latina", en Mario Cimoli (ed.), Heterogeneidad estructural, asimetrías tecnológicas y crecimiento en América Latina, Santiago de Chile, CEPAL-BID, 2005.

Dalum, Bent, Keld Laursen y Bart Verspagen, "Does specialization matter for growth?", Industrial and Corporate Change, vol. 8, núm. 2, Oxford University Press, junio de 1999, pp. 267-288.

Dixon, Robert y Anthony Thirlwall, "A model of regional growth-rate differences on Kaldorian lines", Oxford Economic Papers, vol. 27, núm. 2, Oxford University Press, julio de 1975, pp. 201-214.

Esquivel, Gerardo, "Convergencia regional en México, 1940-1995", El trimestre económico, vol. LXVI (4), núm. 264, México, Fondo de Cultura Económica, 1999, pp. 725-761.

Fuentes, Noé, "Apertura comercial y divergencia económica regional en México", $\mathrm{Co}$ mercio exterior, vol. 53, núm. 10, México, Bancomext, octubre de 2003, pp. 970-978.

Fuentes, Noé y Jorge E. Mendoza, "Infraestructura pública y convergencia regional en México, 1980-1998", Comercio exterior, vol. 53, núm. 2, México, Bancomext, febrero de 2003, pp. 178-187.

Gamboa, Rafael y Miguel Messmacher, Desigualdad regional y gasto público en México, Documento de divulgación 21, BIDIntal, ITD, STA, 2003.

Grossman, Gene y Elhanan Helpman, Innovation and Growth in the Global Economy, Cambridge, MA, The MIT Press, 1991.

Vol. 40, núm. 159, octubre-diciembre / 2009
Hatzichronoglou, Thomas, "Revision of the high-technology sector and product classification", OECD Science, Technology and Industry Working Papers, 1997/2, OECD, 1997.

INEGI, Encuesta Nacional de Ocupación y Empleo (ENOE), México. Disponible en: www.inegi.org.mx/est/contenidos/español/ proyectos/coesme/programas/programa2. asp?clave $=081 \& \mathrm{~s}=\mathrm{est} \& \mathrm{c}=10784$

, Banco de Información Económica, México. Disponible en: http://dgchesyp. inegi.org.mx/cgi-win/bdieintsi.exe

Jungmittag, Andre, "Innovations, technological specialisation and economic growth in the European Union", Economic Papers, núm. 199, Bruselas, Comisión Europea, 2004.

Kaldor, Nicholas, "The case for regional policies", Scottish Journal of Political Economy, vol. 17, núm. 3, noviembre de 1970 , pp. 337-348

, Causes of the Slow Rate of Economic Growth of the United Kingdom: An Inaugural Lecture, Londres, Cambridge University Press, 1966.

Lucas, Robert Jr., "On the mechanics of economic developments", Journal of Monetary Economics, vol. 22, núm. 1, julio de 1988, pp. 3-42.

McCombie, John y Thirlwall, A. P., Economic Growth and the Balance-of-Payments Constraint, Nueva York, St. Martin Press, 1994.

Meliciani, Valentina, Technology, Trade and Growth in OECD Countries. Does Specialisation Matter?, Londres, Routledge, 2001.

Meri, Tomas, "High-tech knowledge-intensive services", Statistics in Focus. Science and Technology, núm. 18, Eurostat, European Communities, 2008.

Messmacher, Miguel, "Desigualdad regional en México. El efecto del TLCAN y otras reformas estructurales", Documento de investigación, núm. 4, Dirección General de Investigación Económica, Banco de México, 2000.

Ocegueda, Juan Manuel, “Análisis kaldoriano del crecimiento económico de los estados de México, 1980-2000", Comercio exterior, vol. 53, núm. 11, México, Bancomext, noviembre de 2003, pp. 1024-1034. 
Rivera Bátiz, Luis A. y Paul Romer, "International trade with endogenous technological change", European Economic Review, vol. 34, núm. 4, Elsevier, mayo de 1991, pp. 971-1001.

Rivera Bátiz, Luis A. y Danyang Xie, "Integration among unequals", Regional Science and Urban Economics, vol. 23, núm. 3, Elsevier, julio de 1993, pp. 337-354.

Romer, Paul, "Endogenous technological change", The Journal of Political Economy, vol. 98, núm. 5, The University of Chicago Press, octubre de 1990, pp. S1-S102.

, "Increasing returns and long-run growth", The Journal of Political Economy, vol. 94, núm. 5, The University of Chicago Press, octubre de 1986, pp. 1002- 1037.
Ros, Jamie, La teoría del desarrollo y la economía del crecimiento, México, Fondo de Cultura Económica, 2004.

Thirlwall, Anthony P., The Nature of Economic Growth. An Alternative Framework for Understanding the Performance of Nations, Edward Elgar Publishing, 2002.

"Regional problems are balance-ofpayments problems", Regional Studies, vol. 14, núm. 5, 1980, pp. 419-425.

,"The balance of payments constraint as an explanation of international growth rate differences", Banca Nazionale del Lavoro Quarterly Review, núm. 128, 1979, pp. 45-53.

Thirlwall, Anthony P. y Robert Dixon, "A model of export-led growth with balance of payments constraint", en J. Bowers (ed.), Inflation, Development and Integration, Leeds, Leeds University Press, 1979. 